\title{
The significance of an employee value proposition in the retention of teachers at selected South African private schools
}

\begin{tabular}{|c|c|}
\hline $\begin{array}{l}\text { Authors: } \\
\text { Karen Swanep } \\
\text { Musawenkosi }\end{array}$ & $\begin{array}{l}\text { oel }^{1} \text { (1) } \\
\text { D. Saurombe }{ }^{2} \text { (1) }\end{array}$ \\
\hline $\begin{array}{l}\text { Affiliations: } \\
\text { 'Department } \\
\text { Southern Busi } \\
\text { Johannesburg }\end{array}$ & $\begin{array}{l}\text { f Management, } \\
\text { hess School, } \\
\text { South Africa }\end{array}$ \\
\hline $\begin{array}{l}2 \text { Department } \\
\text { Psychology an } \\
\text { Management, } \\
\text { Business and } \\
\text { University of J } \\
\text { Johannesburg }\end{array}$ & $\begin{array}{l}\text { f Industrial } \\
\text { d People } \\
\text { College of } \\
\text { conomics, } \\
\text { ohannesburg, } \\
\text { South Africa }\end{array}$ \\
\hline $\begin{array}{l}\text { Correspondin } \\
\text { Musawenkosi } \\
\text { donaynaysauz }\end{array}$ & $\begin{array}{l}\text { g author: } \\
\text { Saurombe, } \\
\text { 24@gmail.com }\end{array}$ \\
\hline $\begin{array}{l}\text { Dates: } \\
\text { Received: } 275 \\
\text { Accepted: } 23 \\
\text { Published: } 23\end{array}$ & $\begin{array}{l}\text { ept. } 2021 \\
\text { Nov. } 2021 \\
\text { Feb. } 2022\end{array}$ \\
\hline $\begin{array}{l}\text { How to cite th } \\
\text { Swanepoel, K. } \\
\text { M.D., 2022, 'T } \\
\text { of an employe } \\
\text { proposition in } \\
\text { of teachers at } \\
\text { African private } \\
\text { African Journo } \\
\text { and Managen } \\
25(1) \text {, a4358. } \\
\text { 10.4102/sajen }\end{array}$ & $\begin{array}{l}\text { is article: } \\
\text { \& Saurombe, } \\
\text { he significance } \\
\text { e value } \\
\text { the retention } \\
\text { selected South } \\
\text { schools', South } \\
\text { l of Economic } \\
\text { ent Sciences } \\
\text { tttps://doi.org/ } \\
\text { s.v25i1.4358 }\end{array}$ \\
\hline $\begin{array}{l}\text { Copyright: } \\
\text { ( 2022. The } \\
\text { Licensee: AOS } \\
\text { is licensed un } \\
\text { Creative Comr } \\
\text { Attribution Lic }\end{array}$ & $\begin{array}{l}\text { uthors. } \\
\text { IS. This work } \\
\text { der the } \\
\text { nons } \\
\text { ense. }\end{array}$ \\
\hline Read online: & \\
\hline 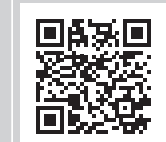 & $\begin{array}{l}\text { Scan this QR } \\
\text { code with your } \\
\text { smart phone or } \\
\text { mobile device } \\
\text { to read online. }\end{array}$ \\
\hline
\end{tabular}

Background: Private schools in South Africa are currently faced with the challenge of retaining a talented pool of teachers. An employee value proposition (EVP) could assist private schools in reducing teaching staff turnover.

Aim: The aim of this study was to investigate the significance of an EVP in the retention of teachers at three selected South African private schools. The study thus sought to answer the following question: What is the significance of an EVP in the retention of teachers at three selected South African private schools?

Setting: Time and money are spent on the recruitment and development of teachers. High turnover of teachers reduces all staff recruitment and staff development efforts to useless financial expenses.

Methods: A qualitative research approach was followed. Semi-structured interviews were used to gather data from teachers at three different private schools in Johannesburg.

Results: The findings showed that most private schools lack a clear and differentiated EVP. Despite their importance, EVPs were often not clearly communicated to staff members and the value of EVPs in the retention of teachers was mostly underestimated.

Conclusion: The research highlighted the deficiencies in the EVPs of most schools. It also emphasised the backlog in the retention of teachers caused by a lack of a proper EVP.

Keywords: teachers; employee value proposition; talent; retention; private school.

\section{Introduction}

\section{Orientation}

The turnover of teachers has become a major concern in educational research and policy analysis during the past decade, mainly because of the demand it creates for replacement (Faremi 2017). In both private and government schools the loss of leadership experience, knowledge, expertise and wisdom has the potential to weaken the institution and affects the performance of the school children.

A study done in Nigeria by Faremi (2017) revealed a significant relationship between strategies aimed at the retention of teachers and job security in private secondary schools. The study highlighted a significant relationship between teacher turnover and job security. It also highlighted a higher rate of turnover in female teachers in the selected private secondary schools. Based on the findings, it was therefore recommended that teacher retention strategies should rely on basic employee value proposition (EVP) principles such as equal workers' welfare packages, good working conditions, teacher mentoring programmes, reward programmes and teacher preparation to ensure job security.

For any school management team, the challenge is to find and retain quality teachers - teachers with the skills, knowledge, experience, competencies and values that provide a match for the roles within the organisation. Teachers look around, think about their circumstances, compare options, and then choose to take up or stay in positions based on the best value offered to them, as characterised by the EVP. An attractive EVP will also ensure the commitment and engagement of employees, the result of which would be better retention (Alloush 2017; SABPP 2019). 


\section{Research purpose and objectives}

The main objective of this research was to investigate the significance of an EVP in the retention of teachers at three selected South African private schools. More specifically, this research sought to determine how significant the role of an EVP is and what the influence of a lack thereof is on the commitment, engagement and retention of teachers at three selected South African private schools.

\section{Research question}

This research sought to answer the following question:

What is the significance of an EVP in the retention of teachers at three selected South African private schools?

\section{Literature review}

\section{The function of the employee value proposition}

An EVP is the holistic package offered by an employer in exchange for the productivity of an employee. According to Kissoonduth (2017), the EVP functions as a dual transaction. On one side you have the employer providing remuneration, employee benefits, performance and recognition incentives, talent development opportunities, work-life initiatives and a healthy organisational culture (South Africa 2019); on the other side you have the employee whose engagement with the EVP determines their level of effort in bringing the vision of the institution to life. The purpose of the EVP is to attract, engage and subsequently retain employees to achieve institutional success (Salau et al. 2018). It is of critical importance that employers should focus on a competitive EVP and a package offering to maintain a competitive edge.

Salau et al. (2018) describe the EVP as the value or benefit an employee derives from their membership of an organisation. It has been suggested that the EVP is a determinant of employee engagement and retention, with a direct effect on critical business outcomes. Employee engagement is the intellectual and emotional attachment that an employee has to their work. It involves rational and emotional factors - what employees think (the mind) and feel (the heart) regarding the organisation. Rational factors refer to aspects like having the necessary tools, resources and support that employees need to perform their jobs. Rationally engaged employees understand how their work contributes to the success of the organisation, and how their roles link to company objectives. Emotional factors refer to the sense of inspiration and accomplishment that employees get from their work. Engaged employees are intellectually stimulated, emotionally inspired, and have a desire to stay with the organisation (Manogharan, Thivaharan \& Rahman 2018).

\section{The talent management strategy}

As competition for talented employees is on the rise, an increasing number of employers are shifting their focus from recruiting talent in the labour market (outside) to exploring the management of the talent of employees at the institution (inside). This implies an optimising of internal processes so that the right talent is available at the right time in the right place in the right capacity to achieve the strategic and operational goals of the institution (Al Aina \& Atan 2020). Talent management is seen as a continuous cycle involving the identification, recruitment, development, engagement, deployment and finally the retention of employees who add value to the institution. The talent management process has an important focus regarding how high-performing and high-potential employees in the institution are managed towards their retention for as long as possible.

Sharif and Islam (2017) encourage employers to be strategic in their policies and procedures and to use and create opportunities to convince their employees that they are employed by a competitive institution. Ghosh (2021) suggests that a regular measurement of whether employees are engaged with their work as well as an analysis of exit interviews would assist the employer to identify gaps in the talent management strategy. Ideally, employers should be flexible in their policies and practices to adapt to the changing needs of talented employees, even if it implies customising the retention mechanisms to suit the unique profile of these employees.

\section{Generational effect}

As different generations of employees are employed at the same time at an institution, it becomes important for employers to understand the unique life experiences and expectations of the Baby Boomers, Generation $X$ and Generation $Y$ employees. Understanding the different generations could present opportunities to gain a competitive advantage in the market, especially if the employer succeeds in adapting the retention strategy to suit the needs of the different generations (Rainie \& Anderson 2017). Hirsch (2017) highlights that Baby Boomers are most likely to remain loyal to their organisations. They are highly respectful of authority, and favour consensus and a stable working environment. They are seen as the generation that is least focused on their career and social awareness.

Generation X employees seek out work-life balance and tend to chase higher salaries and benefits. They are generally independent but require more frequent feedback. They are focused on career advancement but exhibit a greater external locus of control than Generation Y. Pinzaru et al. (2017) highlight that Generation $\mathrm{Y}$ is an optimistic generation, who are driven and demanding of their work environment. They tend not to deliberately seek out job security; they value skills development and are always looking for challenges. They are highly confident and value team interactions as well as the opportunity to take responsibility and make decisions. Although salary is important to support Generation $\mathrm{Y}$ employees' lifestyle, they will accept lower salaries if they believe in the long-term future of the company and if they are directly involved in designing that future. Among them is increased emphasis on corporate philanthropy and social awareness. 


\section{Psychological contract}

Employees' expectations of their new workplace is often aligned to the psychological contract with the employer. Employees create their own psychological contract through their recruitment experience, career development opportunities and reward received for the work that is performed (Kissoonduth 2017). In this contract, employees try to align their expectations of the employer with what the employer offers in the negotiated employment contract. As the nature of this psychological contract is unspoken and subjective, the employer might be challenged in managing the employee's expectations. To limit the misalignment between the two contracts, the employer needs to communicate a consistent message to the employee to build a relationship of trust.

\section{Factors influencing employee engagement and retention in private schools and other educational institutions}

\section{Remuneration}

According to Ashley (2018), remuneration is one of the most important factors that influence employee satisfaction. The study also found remuneration for academics to be comparatively low in comparison to equally qualified employees in other industries and countries. This explains why teachers may tend to leave the industry for better remuneration. When a depressed economy leads to a lack of salary increases, employees' attitudes, such as satisfaction, commitment and intention to leave, are also affected. Compensation is a key reason why academics are leaving teaching; therefore, compensation structures should be customised to retain academics. Uncompetitive remuneration packages result in academics being poached by the private sector (Bwowe 2020).

\section{Discrimination}

Discrimination in the workplace is not always limited to race. In the arena of higher education, examples of gender discrimination are still evident. For example, female employees at South African universities are often overlooked and replaced by their male counterparts. They seldom progress past the level of senior lecturer (Naidu 2018). Data shows that women make up $72.5 \%$ of the teaching staff at South African government schools, but only $37.3 \%$ of the principals on the state payroll are female. The possibility exists that female academics might look for other employment opportunities because they feel that they can't be further promoted.

\section{Unrealistic workloads}

Ashley (2018) presents a discussion of how teachers must work in a demanding environment, while doing complex work. Increased workloads and accountability lead to increased stress levels and dissatisfaction. In 2017, the National Education Union in England conducted a survey regarding the workloads of teaching staff at private schools. The survey found that a fifth of staff are spending the equivalent of four extra working days a week on marking and administration. Nearly two-thirds of the participants remarked that their school has no policies in place to help manage workloads. It was also revealed that $22 \%$ of staff spend the equivalent of two extra working days (over 15 hours a week) on activities related to their job during evenings and weekends. A further $18 \%$ said they spend between 11 and 15 hours a week working outside of core hours. Close to $50 \%$ of the teachers surveyed said they are expected to work extra hours. According to $58 \%$ of the participants, their school has no policy, system, or process in place to help manage workloads (Allen-Kinross 2017).

\section{Staff development}

Various studies prove that training plays a key role in workforce retention. As staff development has become a core issue, so has the need for management training. Bwowe (2020) is of the opinion that insufficient career opportunities and inadequate academic staff development have an impact on academics' career motivation, success and employability. Education leadership should focus on a holistic understanding of how to attract, develop and sustain academic talent. While managers are focused on profits and development of the business, employees are interested in things like personal development, fulfilment and monetary rewards (Bwowe 2020).

\section{Recognition, feedback and communication}

Manogharan et al. (2018) developed a talent retention diagnostic tool to determine the turnover and retention factors with regard to academic staff. Taking the reliability analysis into account, it can be concluded that the compensation and recognition scale is a valid and reliable measure. Of the employees used in the study, $43 \%$ reported inadequate emotional recognition. Inadequate employee recognition has been linked to lower employee engagement and higher turnover intentions in previous studies. The previous authors refer to employees' need for a symbolic reward: they wish to be appreciated, to have a sense of acknowledgement for their loyalty, hard work and commitment.

Osborne and Hammoud (2017) also found that feedback practices within a higher education institution are inadequate and recommended that supervisors provide feedback throughout the year to improve employee engagement. Recent studies have proved that pay and benefits have a weaker relationship regarding encouraging work engagement than recognition, incentives and intangible rewards, and concluded that quality of work, leadership, career development, organisational culture and work-life balance all have a greater impact on work engagement than monetary rewards (Osborne \& Hammoud 2017).

\section{Research design Research approach}

This study adopted a qualitative approach, which was motivated by the fact that eight individuals at three different private schools would be interviewed. The focus of this study 
was on the experiences of members of each school's management team - the deputy head of academics and either one or two subject heads were interviewed at each school.

In this study, semi-structured, one-on-one interviews were used. The interviewer had a series of 12 open-ended questions on an interview schedule developed by the researchers. The interviews were conducted in English and lasted $1.5 \mathrm{~h}$ on average. The sequence of questions asked during each interview varied according to the scope of the answers and issues or themes emanating from the answers. The questions in a semi-structured interview tend to be more broadly framed than those in a structured interview. The interviewer further used probing questions, where necessary, to garner meaningful replies. Qualitative methods are generally more flexible than quantitative methods as they allow greater spontaneity and adaptation of the interaction between the interviewer and the study participant (Mohajan 2018).

Qualitative research seeks to understand a given research topic from the perspective of the people that it involves (Mohajan 2018). It provides complex textual descriptions of how people experience a given research issue. This research falls within the phenomenological design - researching the world through the eyes of those with direct lived experience to discover how they interpret their experiences and make sense of their world (Bryman et al. 2017)

\section{Research strategy}

During the semi-structured interviews, the interviewer used an interview guide with a list of questions covering how the EVP affects the retention of teachers, taking commitment and engagement factors into consideration. Open-ended questions were used with the advantage of participants having the opportunity to respond in their own words and evoking responses that the researcher does not anticipate. Questions that were not included in the guide were also asked, where necessary, to uncover deeper insights.

\section{Research method}

\section{Entrée and establishing researcher roles}

Permission was requested from the principals of various selected private schools in Johannesburg to enter the schools and conduct the interviews. The researchers arranged a meeting with every principal to explain the nature of the research and to gain permission for staff members of the various schools to participate in the interviews. One of the two researchers conducted the interviews and is referred to as 'the interviewer' in the sections that follow.

\section{Research participants and sampling methods}

There are a number of considerations to keep in mind when deciding on the sample size. A compromise usually has to be made between the constraints of time and cost, the need for precision and other considerations. According to Braun and Clarke (2021), larger sample sizes do not necessarily produce greater applicability, as depth may be sacrificed for breadth or there may be too much data for adequate analysis.

This study made use of purposive convenience sampling. In purposive sampling, once the categories and the number of people to be interviewed within each category have been decided on, it is the interviewer's job to select people who fit these categories (Bryman et al. 2017). In this study, eight members of the management teams of three different private schools participated in the interviews. The criteria for participation were as follows: the deputy head of academics and either one or two subject heads at each school. The participants of this study were selected based on their willingness and availability to take part in the data collection process, considering that they fit the criteria.

\section{Data collection methods}

The qualitative data collection was conducted using semistructured interviews, following an interview guide that was developed by the researchers. The interviewer had a list of 12 open-ended questions on EVP and retention, taking commitment and engagement into consideration.

The following questions were included in the interview schedule for this study:

Research question 1: What are the perceptions of teachers of the current application of EVP at South African private schools?

- What are the factors that motivated you to become part of this organisation?

- Do these factors still contribute to your engagement and loyalty towards your employer?

- Do you think the EVP is successfully communicated to teachers and its elements relevant to the personal experiences of employees?

Research question 2: What are the perceptions of teachers of the significance of EVP practices at South African private schools?

- In your perspective, do teachers understand the value of the EVP?

- What are the factors that would make you consider joining another organisation?

- What elements of the EVP would make your job more attractive to you?

Research question 3: Are there any significant differences in the application of EVP practices for teachers at South African private schools based on gender differences?

- Do you think gender plays a role in promotion and career planning opportunities at your organisation?

- Do you believe the EVP at your school should be gender specific and why?

\section{Data recording}

An audio recorder was used to record all interviews. The recordings were transcribed verbatim before data analysis 
could begin. Recording and transcribing interviews has several advantages, as our memory has natural limitations (Loubere 2017). Reviewing recordings and transcripts allows for a more thorough examination of what people said and permits the reviewing of responses. Transcripts of interviews are vital for data analysis and coding. The data should always be organised to make the analysis process easier (Busetto, Wick \& Gumbinger 2020). The researcher must know where the data came from and how it was collected; therefore, all data should be labelled, as fragments of the transcription are needed in support of the themes that are derived from all the data collected (Busetto et al. 2020). The researchers followed these methods in this study.

\section{Strategies employed to ensure data quality and integrity}

As qualitative research produces a considerable amount of data, it became necessary to ensure the easy retrieval of data for detailed analysis later. Audio recordings and transcriptions were made in support of this method of data collection. Notes were also taken during the interviews to provide information regarding the participants' non-verbal communication. Transcriptions of all usable and relevant data were made. Participants were requested to offer remarks concerning the interview transcripts to determine if the themes that were constructed significantly represented the concepts that were examined. According to Braun and Clarke (2021), theme analysis also ensures reliability and validity in qualitative research.

\section{Data analysis}

Qualitative analyses begin in the field as researchers identify problems during observations and interviewing (Bryman et al. 2017). During the interview, the interviewer interacted with the data by making preliminary notes of possible themes that would emerge upon analysis. In this study, the researchers used six steps of thematic analysis, as articulated by Braun and Clarke (2021). These six steps are subsequently delineated. First, familiarisation of the collected data occurred during transcription, to gain insights into participant perspectives. Second, initial codes were manually identified using highlighter colour coding of the various possible codes in the transcript, which were ultimately collated according to colour. Third, various main themes were sought for amid the list of codes, according to the research objectives, and subthemes were collated. Fourth, themes were reviewed and collapsed to achieve a more focused presentation of the findings. Fifth, themes and sub-themes were named and defined to create a logical narrative for the reader to follow. Sixth and finally, a concise and coherent report was generated to give the reader an account of the data obtained, using vivid examples as evidence of each theme and sub-theme.

\section{Reporting style}

The findings of the research were written in narrative form, displaying the themes and various sub-themes that emerged from the study. The themes and sub-themes were substantiated by verbatim quotes obtained from the participants' answers during interviews (Braun \& Clarke 2021).

\section{Findings}

Sixteen themes were identified from the combined responses of the participants. 'Poor salaries' and 'lack of recognition for performance' are the themes that occurred most often. The themes were further clustered into the six main categories of EVP based on the frequencies (F) of the sub-themes (i.e. how many times each theme and sub-theme was mentioned throughout the interviews). The main themes and subthemes are presented in Table 1.

\section{Theme 1: Remuneration}

Remuneration was the theme that occurred most. Below are some excerpts for the themes and sub-themes.

\section{Sub-theme: Poor salaries}

Participants had many concerns over the salaries of teachers at the selected private schools. They highlighted that the salaries as compared to those of the private sector make teachers leave the profession. Some of the responses included the following:

'Salary would definitely be a factor. I would like a better salary and better benefits. Medical aid would be a nice thing to have.' (Participant 2, female, head of department, master's degree, 14 years of work experience in the teaching profession)

'Compared to the marketplace, we are on the low range of earnings. There are no two ways about it. I realised that again when I saw the packages that my daughters have. And I realise that even though I have 30 years of teaching behind me, I am not even able to compete with them.' (Participant 5, female, head of department, bachelor's degree, 30 years of work experience in the teaching profession)

An interesting comment regarding a comparison with government schools' salaries came from one of the participants:

'But there are schools out there that are prepared to offer cell phone allowances, travel allowances and they also offer other benefits like extra incentives for sport coaching. And that's not

TABLE 1: Categories of main and sub-themes.

\begin{tabular}{|c|c|c|c|}
\hline Main theme & Sub-themes & $\mathbf{F}$ & Total \\
\hline \multirow[t]{2}{*}{ Remuneration } & Poor salaries & 9 & 14 \\
\hline & Salaries do not match cost of living & 5 & \\
\hline \multirow[t]{4}{*}{ Work-life balance } & Gender-specific flexibility & 5 & 14 \\
\hline & Management and collegial support & 4 & \\
\hline & Flexible work & 3 & \\
\hline & Generational effect & 2 & \\
\hline \multirow{3}{*}{$\begin{array}{l}\text { Career development } \\
\text { opportunities }\end{array}$} & Gender inequality & 5 & 13 \\
\hline & Personal development & 4 & \\
\hline & Career advancement opportunities & 4 & \\
\hline \multirow[t]{3}{*}{ Employee benefits } & $\begin{array}{l}\text { Availability of leave opportunities (i.e. family } \\
\text { responsibilities, study, sick, maternity) }\end{array}$ & 5 & 13 \\
\hline & Contribution to children's educational cost & 4 & \\
\hline & Contribution to pension fund & 4 & \\
\hline \multirow{3}{*}{$\begin{array}{l}\text { Organisational } \\
\text { culture }\end{array}$} & Workplace culture & 5 & 12 \\
\hline & Job satisfaction and fulfilment & 4 & \\
\hline & Reputation of workplace & 3 & \\
\hline \multirow{2}{*}{$\begin{array}{l}\text { Performance } \\
\text { management and } \\
\text { recognition }\end{array}$} & Lack of recognition for performance & 6 & 10 \\
\hline & Poor performance management & 4 & \\
\hline
\end{tabular}


even private schools, that is state schools. And then, when you add all that together, they are definitely ahead of us. And the myth that we are salary wise above other schools is not true anymore.' (Participant 4, male, head of department, honours degree, 28 years of work experience in the teaching profession)

\section{Sub-theme: Salaries do not match cost of living}

Most participants mentioned that teacher salaries are often not sufficient to cover their costs of living:

'To me the salary and pension contribution are the most important factors. My salary has, however, undergone negative growth over the past few years. I have been at this school for 14 years.' (Participant 6, female, head of department, bachelor's degree, 34 years of work experience in the teaching profession)

'I am the main breadwinner. Housing in this area is extremely expensive. My heart aches for beginner teachers. ... I truly don't know how they survive through the month. We barely do.'(Participant 8, male, head of department, bachelor's degree, 23 years of work experience in the teaching profession)

\section{Theme 2: Work-life balance}

Work-life balance was the theme that was mentioned the second most in this study based on the sub-themes derived from the participants' responses.

\section{Sub-theme: Gender-specific flexibility}

From the interviews it became clear that some private schools are currently meeting female staff members' needs for more work flexibility.

\section{Participant 1 stated the following:}

'When setting the timetable, we keep in mind who have babies at home. We always try to let their classes start later.' (Participant 1 , female, head of department, honours degree, 35 years of work experience in the teaching profession)

Another participant added:

\begin{abstract}
'Some of our younger, married ladies who have small children do tend to be the ones who benefit the most from the EVP. They are, to a certain degree, allowed to select the hours that they work. On their timetables they are being given free certain periods. Certain periods are kept open for them, so that they are able to drop and fetch their children from day-care facilities.' (Participant 3, female, deputy head, honours degree, 33 years of work experience in the teaching profession)
\end{abstract}

\section{Sub-theme: Management and collegial support}

Support from management and colleagues was highlighted as an important contributing factor to the work-life balance of teachers. Participant 2 mentioned:

'What is really nice at this school, is there is a forum for teachers where we can continually bring up any suggestions, any grievance, and challenges that we face and they will try to assist and help us. It is called E-forum. One of the teachers at our school is a representative and we can take any kind of issue to them. For instance, a few years ago there was an issue about maternity leave. A lot of new moms were struggling with UIF [unemployment insurance fund]. Then we went to the E-forum.
The result is that new mummies and daddies are paid full salaries from the board and they don't have to worry about UIF, which I think is an amazing benefit.' (Participant 2, female, head of department, master's degree, 14 years of work experience in the teaching profession)

\section{Participant 8 stated the following:}

'If there is a staff member who had an operation and is incapacitated for a while, either the parents or the staff themselves cook meals and provide meals to that person's family.' (Participant 8, male, head of department, bachelor's degree, 23 years of work experience in the teaching profession)

Participant 6 further shared her personal experience:

'The community spirit within the school is incredible. I've gone through breast cancer twice and management has supported me incredibly through both journeys. The staff as well. I guess that is part of the reason why I am so loyal to this school.' (Participant 6, female, head of department, bachelor's degree, 34 years of work experience in the teaching profession)

\section{Sub-theme: Flexible work}

From the interviews it became clear that having flexibility in their work schedules helps teachers to successfully balance work and personal responsibilities.

\section{Participant 3 stated the following:}

'We get study leave as well. I did a post grad a few years ago and I had to do research collection and they were quite flexible with my timetable, which was very nice.' (Participant 2, female, head of department, master's degree, 14 years of work experience in the teaching profession)

Participant 5 highlighted staff members' frustration due to a lack of flexibility in some circumstances:

\begin{abstract}
'The hardest thing for me in teaching is the limitations of our leave days. There are things like funerals and the need to be with family, or children in hospital, or those kind of things. I understand that there is always the danger of being taken advantage of, but I also think there should be a little more flexibility with that. ... For me the main aspect of joining another organisation would be the inflexibility of my leave. If I could get a little more flexibility there, that would be something that I might consider. Sometimes you have really necessary things to attend to and when you ask for leave, you still feel as if you're asking to go gambling.' (Participant 5, female, head of department, bachelor's degree, 30 years of work experience in the teaching profession)
\end{abstract}

\section{Sub-theme: Generational effect}

From the interviews it became clear that older staff members need a different EVP than those teachers only beginning their careers.

\section{Participant 3 stated the following:}

'It seems to be your middle-aged lady, the category that I fall into, who tends to be doing all the work later on in the afternoons and who tends to be carrying the bulk of the extramural load, because they no longer have children at home and, supposedly, 
they now have more free time on their hands.' (Participant 3, female, deputy head, honours degree, 33 years of work experience in the teaching profession)

Participant 1 stated the following:

'Years of service and degrees do not improve your salary. A young beginner teacher coming in now could earn the same as I am earning after 20 years. That doesn't make sense at all. Experience and qualifications should count more.' (Participant 1 , female, head of department, honours degree, 35 years of work experience in the teaching profession)

\section{Theme 3: Career development opportunities Sub-theme: Gender inequality}

The sub-theme relating to gender inequality was mentioned by five participants.

\section{Participant 8 stated the following:}

'You should not get a higher salary because you are a male. Salaries should not be gender specific - it should be related to your job description and your part in the management team.' (Participant 8, male, head of department, bachelor's degree, 23 years of work experience in the teaching profession)

Participants highlighted unfair career advancement practices that are gender related.

\section{Participant 4 stated the following:}

'I do believe that our organisation is definitely a male-dominated organisation and that females are discriminated against and not seen as management material. And as a male I do think that often female staff members who are better options for certain tasks or roles, are simply overlooked.' (Participant 4 , male, head of department, honours degree, 28 years of work experience in the teaching profession)

Participant 7 supported the above statement:

'To my opinion males are promoted much faster than females at this school. Females are often not recognised for their qualities.' (Participant 7, female, head of department, bachelor's degree, 35 years of work experience in the teaching profession)

Not all participants were in agreement that gender plays a role in career advancement practices. Participant 6 stated the following:

'We are always keen to get more male staff in our school, but if we had two people applying for a leadership position, we would not necessarily take the male. It will be the person with the best qualifications and who's going to be the best fit for the school.' (Participant 6, female, head of department, bachelor's degree, 34 years of work experience in the teaching profession)

\section{Sub-theme: Personal development}

The opportunity for personal development was mentioned by four participants as playing an important role with regard to their loyalty to their current employers.
Participant 2 stated the following:

'I came to this school because I was looking for a new challenge, also a position of growth for myself and more responsibility. I was offered this position. It was time for change and growth.... I do believe I am still challenged. I am still learning new things every day, learning about people, which is really important to me. It is a skill I am not as good at yet; I am better with the task at hand. I am learning a lot about relationships, people management, team management and things like that.' (Participant 2, female, head of department, master's degree, 14 years of work experience in the teaching profession)

Participant 5 added:

'I feel that my current school has been good to me generally; therefore I will not go away. They promoted me, they have given me encouragement to enrich myself academically and to grow. I have been encouraged to do any courses I wanted to.' (Participant 5, female, head of department, bachelor's degree, 30 years of work experience in the teaching profession)

\section{Sub-theme: Career advancement opportunities}

The majority of the participants who are close to retiring age did not mention career development opportunities. The younger participants emphasised advancement opportunities as an important attraction to other schools or jobs in the private sector.

\section{Participant 2 stated the following:}

'I am looking for promotional opportunities. Currently I am head of department, but I am highly motivated and would like even more responsibilities. I am seeking new opportunities like becoming a deputy head or something similar.' (Participant 2, female, head of department, master's degree, 14 years of work experience in the teaching profession)

Participant 4 stated the following:

'If a teacher wants to study further, and it is educational studies which the school will benefit from, then the school pays for those studies. One should however not expect to be promoted. Opportunities for advancement are very rare at private schools.' (Participant 4, male, head of department, honours degree, 28 years of work experience in the teaching profession)

\section{Theme 4: Employee benefits}

\section{Sub-theme: Availability of leave opportunities (i.e. family responsibilities, study, sick, maternity)}

Participant 8 stated the following:

'Teachers who are pregnant obviously get their normal maternity leave. We also give maternity leave to male members of staff. To younger employees this is a very important benefit.' (Participant 8 , male, head of department, bachelor's degree, 23 years of work experience in the teaching profession)

Limited leave days were available at some of the schools, which had a negative impact on staff members' perception that they are supported by management in maintaining a work-life balance. 
'The hardest thing for me in teaching is the limitations of our leave days. There are things like funerals and the need to be with family, or children in hospital, or those kind of things. ... Sometimes you have really necessary things to attend to and when you ask for leave, you still feel as if you're asking to go gambling.' (Participant 5, female, head of department, bachelor's degree, 30 years of work experience in the teaching profession)

\section{Sub-theme: Contribution to children's educational cost}

It also emerged that teachers got a discount on their own children's school fees. Participant 4 stated the following:

'As a parent, I think you get a value-added proposition because you get a huge reduction on your child's school fees. At my school you only pay $10 \%$ of the school fees.' (Participant 4 , male, head of department, honours degree, 28 years of work experience in the teaching profession)

\section{Sub-theme: Contribution to pension fund}

Generally, the participants appeared to be very satisfied with the pension benefits offered by most private schools.

\section{Participant 4 stated the following:}

'The school where I am currently employed contributes really good value in terms of my pension fund. The pension fund contribution of the school is fairly high in comparison to other schools. It does help to have $16.5 \%$ or $15.5 \%$ paid towards your pension fund from the school. And this is definitely value added to my package.' (Participant 4, male, head of department, honours degree, 28 years of work experience in the teaching profession)

\section{Participant 7 added:}

'I was contacted by the head and she offered me a position. I was motivated to join the school by the higher salary and excellent pension plan. At my previous school I had no pension benefits.' (Participant 7, female, head of department, bachelor's Degree, 35 years of work experience in the teaching profession)

\section{Theme 5: Organisational culture}

\section{Sub-theme: Workplace culture}

The findings revealed that a positive work culture contributes to staff members' sense of belonging and happiness at the organisation. As mentioned by one of the participants:

'I've been here for 8 years. I work in a lovely working environment. I am happy to come here every day. It has to do with the overall school culture. There is a positive support culture.' (Participant 2, female, head of department, Master's Degree, 14 years of work experience in the teaching profession)

\section{Participant 6 added the following:}

'I am not planning on leaving the school soon. The ethos of the school is something which I really value. The community spirit within the school is incredible.' (Participant 6, female, head of department, bachelor's degree, 34 years of work experience in the teaching profession)

\section{Sub-theme: Job satisfaction and fulfilment}

The findings revealed that most participants want to feel that their work has purpose and meaning. As Participant 1 mentioned:

'The main thing was the kind of work I was going to do. I wanted to work with children. It was varied work where I felt I could use much of my skills. That was the main reason why I came. ... I love my job and the work I am doing. That's the most important thing. The school provides good service to its clients.' (Participant 1 , female, head of department, honours degree, 35 years of work experience in the teaching profession)

Participant 6 stated the following:

'I would only do a move if I were moving cities. I am incredibly happy here and I couldn't imagine teaching anywhere else. I love my job! I feel that I am appreciated for what I am doing. I am contributing to the lives of many children and that keeps me motivated.' (Participant 6, female, head of department, bachelor's degree, 34 years of work experience in the teaching profession)

\section{Sub-theme: Reputation of workplace}

Three participants mentioned that they heard wonderful things about the school, which made them apply for positions at the school. It was evident from the interviews that they were still proud to be staff members at the school.

Participant 1 stated the following:

'I heard that it's great working here. It had a good reputation as a good place to work. The salary was not amazing. But it really is an excellent school to work at.' (Participant 1, female, head of department, honours degree, 35 years of work experience in the teaching profession)

\section{Theme 6: Performance management and recognition}

\section{Sub-theme: Lack of recognition for performance}

The lack of recognition for performance was mentioned by the majority of the participants during the interviews. The participants discussed how teachers are often not recognised or rewarded for good performance, which in turn lowered their morale.

Participant 4 said the following:

'I don't feel that if I am valued. You have to show that in a salary or in a package that gets amended. Staff that do not contribute and that do not fulfil their job descriptions should be given a lower increase. And the remaining money should be added to the salaries of people that are valued and who work hard and significantly contributes to the success of the organisation.' (Participant 4, male, head of department, honours degree, 28 years of work experience in the teaching profession)

\section{Participant 3 stated the following:}

'It would be very nice to be rewarded if you have met certain criteria, evident in your staff appraisal. One can be rewarded with some time off or even little gifts, such as a Sorbet voucher.' (Participant 3, female, deputy head, honours degree, 33 years of work experience in the teaching profession) 


\section{Sub-theme: Poor performance management}

The schools showed to have no functional performance management system in place, apart from the annual appraisal system.

Participant 1 raised her reservation about her organisation's appraisal system:

'We have an appraisal system. Our annual increases are based on our appraisal and I think it causes a lot of unpleasantness and the board needs to relook it. It is not motivating staff as it is supposed to be. It definitely isn't motivating. It causes a lot of stress, while it is supposed to be a constructive motivational tool. It causes more stress than it is being motivational.' (Participant 1, female, head of department, honours degree, 35 years of work experience in the teaching profession)

\section{Participant 4 added the following:}

'It is a secret oath not to discuss anything relating to salaries. It is also unknown of to discuss one's performance management with management.' (Participant 4, male, head of department, honours degree, 28 years of work experience in the teaching profession)

\section{Discussion}

\section{Outline of the results}

The main objective of this research was to investigate the significance of an EVP in the retention of teachers at three selected South African private schools. The focus in this research fell on the success rate of an EVP in retaining teachers by keeping them engaged, loyal and enthusiastic towards their employers. The following themes have been identified as factors that either contribute to and motivate job satisfaction or compel teachers to leave the current employer or the education industry as a whole: remuneration, work-life balance, career development opportunities, employee benefits, organisational culture, and performance management and recognition.

The findings showed that even in private schools the compensation of teachers remains problematic. Most of the participants were in agreement that teacher salaries are poor when compared to those in the marketplace and often do not keep pace with inflation rates. Remuneration is one of the most important factors that influence employee satisfaction (Ashley 2018).

The participants in this study seemed to be fairly satisfied with their work-life balance. The findings showed that management and collegial support enabled teachers to deal with work and personal demands more effectively. Support from management and colleagues often contributed to the maintenance of work-life balance. The findings of this research re-emphasised that generational and gender segments need to be considered in the construction of an EVP. A differentiated EVP might satisfy different segments in the workplace, ensuring work-life balance for all generations. In line with $\mathrm{Al}$ Aina and Atan (2020), private school management should be flexible in their policies and practices to adapt to the changing needs of their employees. This implies customising the EVP to suit the unique profile of every staff member.

The findings of this research showed that career development opportunities are of high importance to most teachers, especially to the younger members of school management teams. Previous studies have proved that insufficient career opportunities and inadequate teaching staff development have an impact on academics' career motivation and retention (Faremi 2017; Manogharan et al. 2018). Participants stated that they are often not able to benefit from the positive outcomes of career development, as there are generally very few opportunities for promotion at private schools. The findings also revealed that gender discrimination is still evident at some private schools. Female employees are often overlooked when promotion opportunities arise (Naidu 2018). The retention of female teachers becomes problematic at some private schools as female staff members feel that they cannot be further promoted.

The participants in this study mostly appreciated and valued the benefits associated with teaching at a private school. Leave benefits (i.e. maternity, study, family responsibility and health) were highlighted as important factors in maintaining a work-life balance, and in keeping them in the teaching profession. Participants did, however, also highlight the negative effect of limited leave benefits at some private schools and the impact it had on their intention to stay at these schools. Contributions to employees' pension funds and a reduction of the school fees of employees' children were often emphasised as benefits that would retain teachers at private schools. Employee benefits alone will, however, not result in an engaged and retained workforce (Kissoonduth 2017).

The findings of this research showed that workplace culture plays a defining role in the retention of teachers at private schools. The participants were in agreement that a positive school culture contributes to teachers experiencing feelings of belonging, security and overall happiness at the school. Once employees' expectations of their workplace have been met and they feel fulfilled, the psychological contract between the employer and the employee will have been aligned (Kissoonduth 2017). Moreover, the findings also clearly pointed out that participants considered the reputation of the school as an indication of what it would be like to teach there. If the reputation was met, chances were higher that teachers would be retained.

Inadequate employee recognition can be linked to lower employee engagement and higher turnover intentions (Manogharan et al. 2018). The participants in this research highlighted the lack of performance management systems at many private schools and specifically the lack of recognition for performance. They expressed the need to be appreciated and acknowledged for their loyalty, hard work and commitment. The findings of this research made it clear that recognition is a potential employee retention factor. 


\section{Practical implications}

The findings of this research study have important practical implications for the private school industry. School management teams should take notice of the deficiencies in the EVPs at most schools. The findings of this research highlighted the necessity for teacher retention strategies to rely on basic EVP principles such as equal workers' welfare packages, employee benefits, performance and recognition incentives, career development opportunities, work-life initiatives and a healthy organisational culture.

\section{Limitations and recommendations}

The findings of this study cannot be generalised to all private schools in South Africa due to the small sample size of participants. The findings of this research can also not be expanded to the rest of the province or country since it is only applicable to the specific area where the research was conducted. The data were collected at one point in time. This factor further limits the research in terms of creating a cause-and-effect relationship over a long period of time.

Future research should be expanded to private schools in other provinces to enable the comparison of findings. Information gained in this research study should contribute to the currently limited empirical knowledge of the application of EVP in South African private schools. The data can be used in the formulation of strategies to engage and retain teachers in private schools.

\section{Conclusion}

This study sought to establish the significance of the EVP in retaining teachers at three selected private schools. The findings showed that most private schools lack a clear and differentiated EVP. Despite their importance, as uncovered in this study (and substantiated by the literature), EVPs were often not clearly communicated to staff members and the value of EVPs in the retention of teachers was mostly underestimated. Private school management teams should implement, adapt and communicate better the organisation's EVP to all teachers. The EVP should be used as a powerful tool to attract, engage and retain teachers.

\section{Acknowledgements Competing interests}

The authors declare that they have no financial or personal relationships that may have inappropriately influenced them in writing this article.

\section{Authors' contributions}

This article was adapted from the master's research of K.S. who executed and wrote the article, while M.D.S. was the study leader and provided conceptualisation guidelines and editorial inputs.

\section{Ethical considerations}

The authors obtained permission to conduct the research from the head of the private school and, further, ethical clearance from the Southern Business School's research ethics committee to conduct the study was obtained, prior to data collection and the ethical clearance was valid during the entire duration of the data collection phase. Ethical Clearance Number: SBS-20192-0014-M.

\section{Funding information}

This research received no specific grant from any funding agency in the public, commercial, or not-for-profit sectors.

\section{Data availability}

The original data set from which the results of this article were analysed and delineated are available on the researchers' electronic database.

\section{Disclaimer}

The views expressed in the submitted article are the researchers' own and not an official position of the researchers' affiliated institution or funder.

\section{References}

Al Aina, R. \& Atan, T., 2020, 'The impact of implementing talent management practices on sustainable organizational performance', Sustainability 12(20), 8372. https:// on sustainable organizational
doi.org/10.3390/su12208372

Allen-Kinross, P., 2017, Schoolsweek, viewed 10 April 2019, from https://schoolsweek. co.uk/the-pushy-parents-unmanageable-workloadsat-private-schools/.

Alloush, H.A., 2017, 'Evaluating the employee value proposition in academic institutions in Gaza Strip', Unpublished Master's thesis, The Islamic University of Gaza, Gaza strip.

Ashley, C., 2018, 'Internal and external factors that influence the retention of academics in higher education institutions in South Africa', Educor Multidisciplinary Journal 2(1), 86-101.

Braun, V. \& Clarke, V., 2021, 'Conceptual and design thinking for thematic analysis', Qualitative Psychology. https://doi.org/10.1037/qup0000196

Bryman, A., Bell, E., Hirschsohn, P. \& Du Toit, J., 2017, Research methodology business and management contexts, 8th edn., Oxford University Press, Cape Town.

Busetto, L., Wick, W. \& Gumbinger, C., 2020, 'How to use and assess qualitative research methods', Neurological Research and Practice 2, 14. https://doi. org/10.1186/s42466-020-00059-z

Bwowe, P., 2020, 'Employee turnover intention at a historically disadvantaged South African University', Journal of Educational and Social Research 10(6), 162. https:// doi.org/10.36941/jesr-2020-0117

Faremi, M.F., 2017, 'An assessment of teacher retention and job security in private secondary schools in Ogun State, Nigeria', Bulgarian Journal of Science and Education Policy 11(2), 279-293.

Ghosh, P., 2021, What is talent management? Definition, strategy, process and models, viewed 15 November 2021, from https://www.toolbox.com/hr/talentmanagement/articles/what-is-talent-management/.

Hirsch, A.S., 2017, 4 ways for HR to overcome aging workforce issues, viewed 15 November 2021, from https://www.shrm.org/resourcesandtools/hr-topics/ behavioral-competencies/global-and-cultural-effectiveness/pages/4-ways-for-hrto-overcome-aging-workforce-issues.aspx.

Kissoonduth, K., 2017 'Talent management: Attracting and retaining academic staff at selected public higher education institutions', Unpublished doctoral thesis, The University of South Africa, Gaza strip, viewed 15 November 2021, from https://uir. unisa.ac.za/bitstream/handle/10500/24225/thesis_kissoonduth_k. pdf?isAllowed $=y \&$ sequence $=1$.

Loubere, N., 2017, 'Questioning transcription: The case for the Systematic and Reflexive Interviewing and Reporting (SRIR) method [46 paragraphs]', Forum Qualitative Sozialforschung / Forum: Qualitative Social Research 18(2), available from http://nbn-resolving.de/urn:nbn:de:0114-fqs1702152. 
Manogharan, M., Thivaharan, T. \& Rahman, R., 2018, 'Academic staff retention in private higher education institute - Case study of private colleges in Kuala private higher education institute - Case study of private colleges in Kuala org/10.5430/ijhe.v7n3p52

Mohajan, H.K., 2018, 'Qualitative research methodology in social sciences and related subjects', Journal of Economic Development, Environment and People 7(1), 23-48. https://doi.org/10.26458/jedep.v7i1.571

Naidu, E., 2018, 'Universities body to probe gender imbalance at the top', University World News, viewed 15 November 2021, from https://www.universityworldnews. com/post. php?story $=20180725103923330$.

Osborne, S. \& Hammoud, 2017, 'Effective employee engagement in the workplace', International Journal of Applied Management and Technology 16(1), 50-67. https://doi.org/10.5590/IJAMT.2017.16.1.04

Pinzaru, F., Vatamanescu, E-M., Mitan, A., Vitelar, A., Savulescu, R., Noaghea, C. et al., 2017, 'Millennials at work: Investigating the specificity of generation Y versus othe generations', Management Dynamics in The Knowledge Economy 4, 173-192.
Rainie, L. \& Anderson, J., 2017, The future of jobs and jobs training, viewed 15 November 2021, from https://www.pewresearch.org/internet/2017/05/03/ the-future-of-jobs-and-jobs-training/.

SABPP, 2019, Employer value proposition, viewed 11 November 2021, from https://cdn.ymaws.com/www.sabpp.co.za/resource/resmgr/website_files_1/ publications/fact_sheets/fact_sheet_2019/fact-sheet_february-2019_wit. pdf.

Salau, O.P., Osibanjo, A.O., Adeniji, A.A. \& Oluwatunmise, O., 2018, 'Datasets on employee value proposition (EVP) and performance of selected fast movin consumer goods (FMCGs) firms in Nigeria', Data in Brief 19, 1907-1911. https:// doi.org/10.1016/j.dib.2018.06.027

Sharif, A. \& Islam, M.T., 2017, 'Branding for successful employment: A practical approach', Global Journal of Management and Business Research 17(3), 19-28.

South Africa, 2019, 'SA board for people practices', Employer Value Proposition 2019(1), 1-12. 